\title{
A Note to Prospective Authors
}

A

lthough it may seem obvious, it is worth emphasizing that one of the most important tactics for facilitating the successful placement of an essay in a publication is to follow the directions for contributors. Theological Librarianship, for instance, has requirements for length, format, deadlines, and other particulars. These guidelines are posted on the Theological Librarianship website and may also be obtained by contacting the editors. Submissions that most clearly adhere to the published instructions and are submitted in a timely fashion are more likely to receive priority for slots in the peer review process than are those that will obviously require extensive revision. Submission guidelines are not idle musings, but vital directions. For example, peer reviewers are asked to determine whether the manuscript is "appropriate in length," and the basis for this judgment is the word count established by the editorial team. This is not to say that manuscripts that are at the draft stage or incomplete will not be considered, but that submissions that require extensive revision, topic development, and structural considerations will be delayed in the publication cycle.

In addition to heeding the submission guidelines, turning to an issue of the journal and viewing a few of the published essays is often a helpful exercise. For instance, format and length requirements are often easily understood by perusing an article or sample essay previously in the journal. Viewing prior essays may also help prospective authors on a number of other levels. For example, the choice of a topic for an article or bibliographic essay may be simplified by observing the contents of previously published issues. Theological Librarianship wishes to demonstrate the breadth of the field of theology/religious studies and the craft of librarianship. When in doubt whether the editors will be interested in a topic, it is best to contact them first before writing and submitting an article. This is also the case if an author is considering a series of articles on a theme. The editors will normally take the initiative in developing entire issues devoted to a single theme but will also consider such proposals from an author (or group of authors). Again, contact the editors first.

Along with these points, the careful prospective author will be wise to focus on three additional areas.

First, the timeliness of the topic is important. A contributor who reviews a body of literature that is dated or elects to write on an obsolete issue may not be successful in placing a piece in a journal. Of course, there may be exceptions. Issues that are passé for librarians in one part of the world may yet be of relevance to librarians elsewhere. Articles or essays on libraries and librarianship in less-developed parts of the world will always be considered.

Second, authors should be sensitive to the diverse audience to which Theological Librarianship is addressed. This journal reaches a membership that is interdenominational, includes adherents from a variety of world religions, and represents a wide range of libraries from the large university resource center to the small boutique-sized standalone institution. Manuscripts should be written so as to avoid marginalizing potential readers.

Finally, authors are requested to be patient with the editors and the editorial process. The peer-review process especially may be lengthy or nerve wracking, or both. Requests for revisions or rewrites should never be taken as personal affronts. The editorial team, for one thing, is looking at a journal issue holistically. As a result, some requested changes may relate to how well an individual manuscript fits with others that are planned for the same issue, or with another agenda that the editors have in mind. Authors who can accept such feedback with aplomb and flexibility may even find the process enjoyable and educational. In other words, patience, perseverance, and good humor will all work to the advantage of contributors. 